\title{
Da reinterpretação de sistemas tradicionais de uso da terra à construção social de mercados com os agriculto- res familiares da roça de toco de Biguaçu-SC
}

\section{From the reinterpretation of traditional systems of land use to the social construction of markets with the farmers from the slash-and -burn of Biguaçu, SC, Brazil}

Cíntia Uller-Gómez - Doutora em Ciências Humanas. Analista ambiental da Fundação de Meio Ambiente de Santa Catarina (FATMA). E-mail: cintiaug@gmail.com

Reney Dorow-Mestre em Agronegócios. Analista de mercados do Centro de Socioeconomia e Planejamento Agrícola da Empresa de Pesquisa Agropecuária e Extensão Rural de Santa Catarina (Epagri/CEPA). E-mail: reneydorow@epagri.sc.gov.br

Ivonete Lenir Stern - Nutricionista e especialista em Nutrição Clínica. Bolsista do CNPq no Projeto Rede Sul Florestal. E-mail: ivonete.stern@gmail.com

Eliane Bauer - Engenheira Agrônoma e mestre em Agroecossistemas. Bolsista do CNPq no Projeto Rede Sul Florestal. E-mail: eliane_bauer@yahoo.com.br

\begin{abstract}
Resumo
Apresentamos a importância do sistema de agricultura de roça de toco para a conservação da biodiversidade e para a segurança alimentar. Com base em trabalhos desenvolvidos com agricultores de Biguaçu, no Sul do Brasil, indicamos como os produtos oriundos desses sistemas podem alcançar mercados diferenciados, gerando melhoria de renda e autoestima. Analisamos o acesso dos produtos ao mercado, antes e depois do desenvolvimento de um processo participativo de planejamento, que resultou em inovações organizacionais, de gestão e de produto. Destacamos os procedimentos adotados por meio da cooperação entre organizações de pesquisa, de ensino, de extensão e de meio ambiente, que permitiram a regularização ambiental do sistema, a saída dos agricultores da clandestinidade e a criação de uma marca coletiva denominada "Valor da Roça". Aponta-se para os desafios ainda presentes relativos ao aprimoramento do processo de comunicação com os consumidores e demais integrantes do mercado, como os órgãos ambientais.
\end{abstract}

\section{Palavras-chave}

Agricultura. Desenvolvimento sustentável. Renda. Corte e queima. Cadeias produtivas.

\begin{abstract}
We present the importance of the slash-and-burn system for the conservation of biodiversity and for food security. Based on studies carried out with family farmers of Biguaçu, South of Brazil, we present how the products from these systems can achieve differentiated markets, increasing the farmers' income and their self-esteem. We analyze the access of these products to the market before and after a participatory planning that resulted in organizational, product and management innovations. We highlight the procedures adopted through the cooperation between research, teaching, environmental and rural extension organizations, which allowed the environmental regularization of the system, the exit from clandestinity e the creation of a collective brand called "Valor da Roça" (Value of the Farm). We point the currently present challenges related to the improvement of communication with consumers and other participants of the market, such as the environmental organisms.
\end{abstract}

\section{Keywords}

Agriculture. Sustainable development. Income. Slash-and-burn. Supply chains. 


\section{INTRODUÇÃO}

Trabalhos recentes têm pontuado a importância econômica, social e ecológica dos sistemas tradicionais de uso da terra, aqui entendidos como formas de uso da terra e dos recursos naturais, pautadas no saber tradicional e historicamente construídas. Com essa denominação nos aproximamos do termo “populações tradicionais", utilizado por Arruda (2000, p. 274) para designar aquelas populações que

[...] apresentam um modelo de ocupação do espaço e uso dos recursos naturais voltados principalmente para o autoconsumo, com fraca articulação com o mercado, baseado em uso intensivo de mão de obra familiar, tecnologias de baixo impacto e, habitualmente, de base sustentável (ARRUDA, 2000, p. 274).

Esses autores completam a abordagem associando o termo acima à noção de "campesinidade" (WOORTMANN, 1990), que seria uma forma simbólica de conceber a articulação entre a terra, o trabalho e a família, mais ou menos presente entre os agricultores familiares, mas sempre de forma articulada, e peça central no seu discurso - a terra nunca é pensada independentemente do trabalho e da família.

Com esses dois termos, vamos nos referir a dois sistemas tradicionais de uso da terra: a roça de toco e os bracatingais. Muitos trabalhos abordam a importância dos sistemas tradicionais para a produção voltada ao autoconsumo. Neste texto, a despeito da inquestionável importância desse aspecto, temos o objetivo de discutir a possibilidade de que esses sistemas tradicionais sejam fonte de renda monetária para famílias rurais. Para tanto, apresentamos o referencial teórico já mobilizado para formalizar a produção tradicional de agricultores de Biguaçu (SC), bem como as estratégias organizacionais promovidas, que lhes permitiram alcançar mercados alternativos e melhorias de renda e autoestima.

\section{O POTENCIAL E A NECESSIDADE DE VALORIZAÇÃO DOS SISTEMAS TRADICIONAIS DE USO DA TERRA}

No que diz respeito à roça de toco, outros termos também são usados na literatura para designá-la, como agricultura itinerante, coivara, pousio ou cortee-queima. Embora existam variações, de um modo geral, a vegetação de uma pequena área de floresta é derrubada e queimada visando preparar e fertilizar a terra para o cultivo de espécies agrícolas por um curto intervalo de tempo, 
geralmente de um a três anos. Após a colheita, a área é deixada em pousio por um longo período, que normalmente varia de dez a vinte anos.

Van-Vliet et al. (2012) afirmam que até a segunda metade do século XX a roça de toco foi o sistema de uso da terra dominante nos trópicos, e continua ainda hoje sendo um importante meio de subsistência. Fox et al. (2009) identificaram uma mudança muito acentuada ou o abandono das práticas tradicionais de uso da terra no Sudeste da Ásia depois da Segunda Guerra Mundial. Buscando entender as razões dessa mudança, esses autores constataram que essas práticas estão amparadas em um contexto mais amplo de transições político-econômicas e político-ecológicas que preconizam a agricultura sedentária como modelo e a promoção da agricultura industrial, como também defendem que outros processos de grande escala foram importantes nessa mudança, entre eles a ascensão e integração das políticas e práticas associadas à disseminação da produção capitalista e do comércio, além da gestão científica e burocrática da terra.

Padoch e Pinedo-Vasquez (2010) afirmam que poucas características da roça de toco se enquadram em uma categoria convencional de manejo sustentável. Por conta disso, ressaltam que este sistema tem sido condenado, criminalizado, e que esforços para eliminar a roça de toco são comuns em programas de conservação e de desenvolvimento.

Como resultado, nas últimas décadas a roça de toco está desaparecendo ou sendo substituída por outras formas de uso da terra, o que se acentuou no período da revolução verde. Uma análise global publicada recentemente (VANVLIET et al., 2012) mostrou que a roça de toco diminuiu muito em regiões onde o fácil acesso aos mercados tem incentivado a agricultura intensiva, com o cultivo de várias espécies de maior valor comercial. O estudo mostrou ainda que as políticas de conservação concentradas na restrição ao desmatamento da floresta também têm acelerado o desaparecimento da roça de toco em diversas áreas.

Em Santa Catarina, esse sistema de uso da terra também foi muito importante. Siminski e Fantini (2007) afirmam que este sistema era predominante nos pequenos estabelecimentos rurais em grande parte deste Estado, até a publicação do Decreto 750, em 1993, a partir do qual foi permitido apenas o corte raso de fragmentos florestais em estágio inicial de regeneração.

Uller-Gómez e Gartner (2008), por sua vez, identificaram também as restrições ambientais e a falta de assistência técnica aos agricultores tradicionais entre os fatores que colaboraram para o declínio da roça de toco na região da Grande Florianópolis. Nessa região, no sistema tradicional de roça de toco produz-se aipim, farinha de mandioca e carvão vegetal, muitas vezes em situação de absoluta clandestinidade. 
Nessa região, o sistema tem sido historicamente dominante, assegurando os meios de subsistência de grande parte dos agricultores que vivem em áreas declivosas. No entanto, constatou-se que houve um período em que ocorreu uma intensificação do sistema e a queda da fertilidade do solo; foi quando o plantio de espécies arbóreas nativas, por iniciativa dos próprios agricultores, permitiu a regeneração da floresta nativa nessas áreas (BAUER, 2012, LUCA, 2011; ULLERGÓMEZ; GARTNER, 2008). Não obstante, a roça de toco está claramente em declínio na região. Estudo realizado por Bauer (2012) apontou que, nas duas últimas décadas, grande parte da terra antes ocupada por um mosaico de áreas agrícolas e florestas em diferentes estágios de sucessão - típico do sistema roça de toco - vem sendo convertida em pastagens e plantio de eucalipto. Restrições legais ao uso da floresta nativa, bem como a falta de mão de obra, causada pelo êxodo rural e envelhecimento dos agricultores, foram apontadas como as principais causas dessas mudanças.

Outro sistema tradicional de uso da terra muito importante no Sul do Brasil são os bracatingais, que às vezes também aparecem combinados com a roça de toco.

A bracatinga (Mimosa scabrella Bentham) é uma espécie arbórea pioneira, que ocorre naturalmente do sul de São Paulo ao norte do Rio Grande do Sul (ROTTA; OLIVEIRA, 1981 apud MAZUCHOWSKI, 2012). Os bracatingais, por sua vez, são formações florestais com predominância da bracatinga sobre as demais espécies, em todas as fases de desenvolvimento, florística e estruturalmente distintas das florestas nativas, resultantes de intervenções realizadas para a promoção da bracatinga, tais como cuidados para a manutenção do banco de sementes no solo em longo prazo, promoção da germinação das sementes da espécie, adubações, desbastes, desrama, controle de formigas, controle de acesso de gado e/ou escalonamento de corte, entre outras (Lei Estadual 16.342/2014) (SANTA CATARINA, 2014).

Nesses termos, Steenbock e Reis (2013) argumentam que o significativo número de intervenções intencionais para a formação e manejo dos bracatingais indica que essas formações são paisagens fortemente manejadas, portanto mais próximas de artifícios humanos do que de florestas propriamente nativas. Como acontece na roça de toco, esses autores destacam que o manejo de bracatingais ocorre no regime da economia familiar, sendo muito presente nos assentamentos de reforma agrária do noroeste catarinense, iniciados na década de 1980. Nesses assentamentos, os bracatingais se constituem como a principal atividade econômica, principalmente porque geram lenha para a produção de carvão vegetal. 
Steenbock e Reis (2013) destacam também que as normativas ambientais vigentes não contemplam essa prática tradicional de uso da floresta, e que, no entanto, o manejo praticado pelos agricultores apresenta mais elementos conservacionistas do que os atuais instrumentos legais. Ressaltam, ainda, que a manutenção dos bracatingais depende da possibilidade de que o agricultor obtenha renda através dele.

Mazuchowski (2012) relata a existência de bracatingais cultivados no Paraná desde 1909, onde adotam, já nos primeiros anos, a prática de retirada de estacas para horticultura; e em bracatingais com cinco anos de idade, ocorre a retirada de escoras para construção civil, consideradas de muito boa qualidade.

Em Biguaçu (SC), Luca (2011) identificou a introdução da bracatinga na região, no sistema de roça de toco, como uma estratégia adaptativa desenvolvida pelos agricultores para prover lenha para abastecer a cozinha e os engenhos de farinha, após um período de exaustão das terras, devido à diminuição do tempo de pousio causada pela pressão populacional. No entanto, diante das restrições legais para uso da floresta nativa com o tempo de pousio desejado, este autor verifica que recentemente os agricultores vêm desenvolvendo uma nova estratégia adaptativa: o plantio de espécies florestais exóticas.

Desse modo, esses dois sistemas tradicionais geram renda na agricultura familiar, de forma ecologicamente inteligente, mas, no entanto, configuram-se como irregulares perante a complexidade aparente das normas ambientais atuais.

Essa irregularidade deixa os agricultores em situação de extrema fragilidade social, especialmente quando se trata do carvão vegetal, devido à associação direta produto com o "desmatamento". Ao analisar a cadeia produtiva do carvão em assentamentos de reforma agrária do noroeste catarinense, com a utilização de lenha oriunda de bracatingais manejados, Steenbock (2009) destaca a dependência dos agricultores em relação aos intermediários e o baixo preço recebido pelo produto. Nesses assentamentos, a produção de carvão é destinada principalmente às indústrias siderúrgicas. Nestes casos, circula com "notas frias" de carvão derivado de eucalipto ou de pinus. Quando é destinado ao comércio varejista, o produto é embalado por um intermediário, que geralmente o acondiciona em embalagens de carvão de eucalipto.

O trabalho de Uller-Gómez e Gartner (2008) apontaram que os agricultores de Três Riachos (Biguaçu-SC) que praticam o sistema de roça de toco tinham uma relação de dependência com os intermediários para quem vendiam seus diversos produtos (com exceção da farinha de mandioca) e destacaram o baixo preço pago aos produtores. Carrieri (2010), ao focar a comercialização do carvão vegetal produzido por esses agricultores, constatou que este chegava ao mercado 
de duas formas: "esquentado"" em embalagens formais; ou de forma irregular, reutilizando embalagens de cimento. A autora verificou que, embora no mercado informal e clandestino, os consumidores apreciavam o carvão em "sacos de cimento" e sabiam a sua procedência. A mesma autora salientou, também, que esses intermediários eram produtores ou ex-produtores de carvão, parentes ou vizinhos dos agricultores, e destacou as relações de reciprocidade e confiança existentes entre produtores e intermediários.

Ampliando o seu olhar para outros dois municípios, Carrieri (2014) verificou que em Santa Rosa de Lima (SC) o carvão sempre chega ao mercado em embalagens formais, mesmo que nem sempre seja produzido de forma regularizada, passando sempre por intermediários que embalam e distribuem a produção; é vendido como carvão de eucalipto, embora muitas vezes seja produzido, em parte, com madeira da mata nativa. No assentamento Sonho de Rose, em Bituruna, no sul do Paraná, Carrieri (Op. cit) registrou a produção de carvão a partir da lenha de bracatingais, verificando uma inserção ainda menor dos agricultores na cadeia de comercialização. Neste caso, os agricultores se limitavam a produzir o carvão e alegavam desconhecer detalhes do seu destino.

A mesma autora calculou os valores aproximados recebidos pelos produtores de carvão nos três municípios: Biguaçu, R\$ 0,45/kg; Santa Rosa de Lima, R\$ 0,33/kg; e Bituruna, $R \$ 0,23 / \mathrm{kg}$ - e sugere que quanto menos o produtor está inserido na cadeia de comercialização, menor é o preço que recebe pelo seu produto.

Existem poucos trabalhos dedicados à análise da inserção dos produtos da roça de toco no mercado. A esse respeito, vale destacar a análise sobre a roça de toco ao redor do mundo realizada por Van-Vliet et al. (2012). Esses autores constatam que apesar das dificuldades aqui pontuadas, o sistema persiste em regiões onde os agricultores têm pouco acesso a investimentos e oportunidades de mercado. Em algumas áreas a roça de toco continua sendo importante, simplesmente porque a agricultura intensiva não é uma opção viável, por exemplo, em terrenos declivosos ou solos com baixa fertilidade; ou ainda quando as densidades populacionais e/ou as demandas do mercado de alimentos estão baixas (VAN-VLIET et al., 2012).

Os mesmos autores constataram um conjunto de consequências negativas nas regiões do globo em que esse sistema desapareceu, entre elas: insegurança alimentar, aumento de conflitos, dificuldades de acesso à terra e perda da identidade cultural.

\footnotetext{
Os agricultores usam o termo "esquentar" para se referir ao envasamento do carvão produzido de forma irregular em embalagens formais. Com essa nova forma de apresentação, o produto adquire "roupagem" adequada para acessar o mercado formal.
} 
Na Mata Atlântica, o sistema roça de toco é realizado desde os tempos pré-colombianos (DEAN, 1997), e ainda está presente em muitas comunidades tradicionais de agricultores (ADAMS et al., 2013). Especificamente na região do Vale do Ribeira, no estado de São Paulo, domínio da Mata Atlântica, Adams et al. (2013) verificaram que nos locais onde a roça de toco desapareceu houve diminuição da agrobiodiversidade, com uma redução de $52 \%$ das variedades vegetais; aumento do uso de agrotóxicos e fertilizantes sintéticos; redução da heterogeneidade da paisagem; maior dependência do mercado (comprometimento da renda) para aquisição de alimentos; redução da capacidade de retornar à roça (resiliência) em caso de necessidade, devido à perda da agrobiodiversidade e do etnoconhecimento, além do fato de que, quando por ventura se pretende voltar a fazer roça, as áreas florestadas já superaram a idade legal para uso.

A despeito dos trabalhos acadêmicos evidenciarem que a produção de alimentos em sistemas tradicionais é destinada ao autoconsumo e somente os excedentes ao mercado, pontuamos que em Santa Catarina há bons exemplos de que esses sistemas podem gerar renda. Por outro lado, apesar do seu potencial ecológico, os agricultores que os praticam estão em situação social muito fragilizada e com inserção muito deficiente na cadeia de comercialização.

Em outro sentido, se considerarmos o pressuposto da Nova Sociologia Econômica, de que as decisões econômicas são sempre influenciadas pelas redes sociais, podemos pensar em estratégias que contribuam para transformar essa situação, fazendo com que os produtos oriundos dos sistemas tradicionais sejam também reconhecidos e valorizados em mercados mais distantes, agregando valor à prática tradicional.

Com base nesse pressuposto, diversas iniciativas têm sido desenvolvidas no município de Biguaçu (SC), visando à valorização dos produtos tradicionais derivados do sistema de roça de toco, mediante o acesso a mercados diferenciados, conforme relatamos a seguir.

\section{REFERENCIAL TEÓRICO-METODOLÓGICO}

Para melhor compreender e tentar mudar a situação de irregularidade dos agricultores familiares praticantes do sistema roça de toco, diversos projetos desenvolvidos desde 2009, em Biguaçu, têm promovido a reinterpretação e revalorização da roça de toco, e já são notáveis as evidências de reversão da tendência de desaparecimento desse sistema tradicional de uso da terra na região. Dentre as estratégias para viabilizar essa revalorização, buscou-se promover, 
junto aos agricultores, a reflexão sobre a situação dos produtores e a capacitação desses agentes para que pudessem realizar a gestão de todas as etapas do sistema de produção, bem como a diminuição da assimetria informacional ${ }^{2}$ frente ao mercado consumidor, por meio da inovação organizacional e da comercialização diferenciada dos produtos.

O trabalho de Carrieri (2010) ressalta que as relações de confiança estabelecidas entre os produtores de carvão vegetal e os intermediários de Três Riachos (Biguaçu-SC) deveriam ser consideradas nas propostas de intervenção voltadas para a melhoria da situação daquela população. $\mathrm{O}$ mesmo trabalho também indicava que o carvão tinha atributos de qualidade já reconhecidos pelo consumidor, advindos da qualidade intrínseca do produto.

Assim, buscou-se o amparo teórico-metodológico para fundamentar uma proposta de intervenção com o objetivo de valorizar não somente dos os atributos de qualidade dos produtos, mas, sobretudo, o processo de produção. Ou seja, procurou-se valorizar o sistema de uso da terra (roça de toco) que até então se configurava como uma desqualificação ou depreciação, mas que, ao mesmo tempo, diante dos novos olhares mundiais sobre a roça de toco, poderia se converter em uma oportunidade de melhor inserção nos mercados.

No caso dos produtos da roça de toco de Biguaçu, estávamos diante de um caso exemplar do que Wilkinson (2008, p. 94) buscou referir quando discorreu sobre a dificuldade de expansão da produção para produtores que antes comercializavam somente em circuitos baseados em relações sociais fortes, em que "parentesco, vizinhança conhecimentos pessoais e transações repetidas confirmam reputações e consolidam lealdade". Segundo o autor, "o desafio da expansão da produção não se reduz ao gerenciamento de quantias maiores, nem aos problemas ligados aos custos fixos mais onerosos, mas implica a extensão do mercado além da rede social", chamando a atenção para a noção de "laços fracos" (GRANOVETTER, 1973), que "aponta para a importância da mobilização de outras redes sociais que podem dar amparo aos atores locais" (WILKINSON, 2008, p. 95). Assim, o autor alerta que a maneira "como negociar essa ruptura entre mercado e rede social se torna o desafio fundamental" (Ibid., p. 94).

Nestes termos, em Biguaçu persistia a produção de carvão e alimentos no sistema roça de toco, devido ao embeddedness (GRANOVETTER, 1973), ou seja, aos laços fortes estabelecidos, permitiam que os produtos conseguissem mercado, mesmo produzidos de forma irregular (especialmente o carvão). Neste

2 Santos et al. (2007 apud NASCIMENTO; REGINATO, 2008, p. 34) definem a assimetria da informação "como sendo a diferença de informação existente em uma relação contratual entre o agente e o principal em função de uma parte possuir mais informação do que a outra, ou seja, há informação oculta (bidden information)". 
aspecto, destacamos as relações com os intermediários, ao mesmo tempo, um misto de confiança e dependência ${ }^{3}$.

Por outro lado, trabalhar de forma regularizada exigia a adaptação às determinações legais e esforços para a construção de mercados baseados em novas redes sociais, para que os produtos fossem mais bem remunerados. Evidenciavase, ainda, a necessidade de aumentar a remuneração pelos produtos, de tal forma que o uso parcimonioso da floresta, com exploração em pequena escala e controlada, pudesse gerar renda capaz de atender dignamente as demandas das famílias. Assim, a criação de mercados, para além das redes sociais já estabelecidas, apresentava-se como uma exigência e ao mesmo uma possibilidade para que o uso tradicional da floresta alcançasse um amplo reconhecimento, viabilizando, assim, a sua perpetuação.

No caso da criação de mercados para os produtos da roça de toco, estão em jogo não apenas os agentes relacionados ao consumo, mas também um conjunto de organizações que têm ingerência (direta ou indireta) sobre o sistema de produção e precisam ser entendidas como atores desse "novo mercado" em construção, com destaque aos agentes públicos de extensão, de licenciamento e de fiscalização ambiental.

Wilkinson (2008, p. 101) defende que quando se pretende expandir a comercialização para além das fronteiras da rede social dos produtores, são necessários "mecanismos e formas de sinalização de qualidade que substituam a falta dos conhecimentos tácitos da rede de origem". Ou seja, o mercado dos produtos da roça de toco deveria extrapolar os limites da rede social de origem. Para tanto, deveriam ser firmados acordos que permitissem que a qualidade dos produtos fosse igualmente reconhecida e valorizada nos mercados em que as relações de proximidade inexistem.

Partindo desses pressupostos, a comercialização dos produtos da roça de Biguaçu tem sido analisada com base no enfoque de cadeias produtivas. E as intervenções voltadas à agregação de valor foram amparadas especialmente no enfoque de cadeias curtas, conforme as reflexões apresentadas a seguir.

Segundo Parent (apud BATALHA, 1997), a cadeia produtiva é a soma de todas as operações de produção e de comercialização, para passar de uma ou várias matérias-primas de base a um produto final, até que um produto chegue às mãos de seu usuário - seja ele um particular ou uma organização. Este autor propõe a análise da cadeia em três grandes macrossegmentos:

3 Especificamente no caso do carvão, o embeddedness pode ser percebido nos aspectos negativos das relações comerciais existentes também nos outros locais já mencionados, sobretudo nos assentamentos de Reforma Agrária, onde o poder do intermediário se estendia além das transações sobre o carvão. 
Comercialização: Representa as empresas que estão em contato com o cliente final da cadeia de produção e que viabilizam o consumo e o comércio dos produtos finais (supermercados, mercearias, restaurantes, cantinas etc.).

Industrialização: Representa as firmas responsáveis pela transformação das matérias-primas em produtos finais destinados ao consumidor.

Produção de matérias-primas: Reúne as firmas que fornecem as matériasprimas iniciais para que outras empresas avancem o processo de produção do produto final (agricultura, pecuária, pesca, piscicultura etc.) (BATALHA; SILVA, 2012, p. 7).

No entanto, este conceito não abrange as particularidades das diversas formas de comercialização existentes na agricultura familiar. Assim, quando o agricultor não realiza a comercialização direta ao consumidor final, entregando o seu produto a um intermediário, utilizamos o termo "cadeia longa", com o propósito de diferenciá-la das cadeias curtas ou circuitos curtos definidos a seguir.

Para que a análise pudesse englobar os diferentes tipos de comercialização, incluindo a venda direta e os circuitos informais, baseamo-nos na proposta de Marsden, Banks e Bristow (2000) e Renting, Marsden e Banks (2003), que propõem uma tipologia para as chamadas "cadeias curtas", destacando três tipos principais de cadeias agroalimentares curtas, que apresentam as seguintes características:

- Face a face - Configura-se como a venda direta ao consumidor. As formas podem variar desde a venda no estabelecimento produtivo (fazenda agrícola, fazenda marinha) a feiras de produtos agrícolas, entrega em domicílio, venda postal ou ainda e-comerce;

- Proximidade espacial - Configura-se a partir de unidades de varejo com identidade local, como comércios ligados a rotas temáticas, eventos especiais, feiras do comércio local, restaurantes, serviços de alimentação e culinária típica;

- Espacialmente estendida - Inclui o processo de certificação, rótulos e identificação; representa efeitos da reputação, incluindo mecanismos como certificação "fair trade", processos de certificação e indicação geográfica.

Em alguns casos, também nos foi esclarecedora a noção de "circuito curto" sugerida por Chaffotte e Chiffoleau (2007) para denominar circuitos de distribuição com no máximo um intermediário entre o produtor e consumidor, não havendo prejuízos aos extremos do circuito. Além do mecanismo de venda direta, o intermediário considerado pelos autores estaria no contexto da produção e consumo, podendo ser um representante coletivo (cooperativa ou associação) ou um comércio especializado ou, ainda, outro produtor que se 
encarrega de estabelecer a ponte com o consumidor. Aubri e Chiffolleau (2009) ajustaram esse primeiro conceito sugerindo o termo "circuitos de proximidade", momento em que incorporam a temática territorial do alimento, embutindo os relacionamentos, as questões sociais de distância geográfica, aproximando o consumidor do produtor.

Independentemente das diferentes nuances entre os conceitos, os circuitos ou cadeias curtas oferecem um novo olhar possível para análise das relações entre produtores e consumidores, o que, em seu conjunto, corrobora o que Wilkings (2005) e Levkoe (2006) apresentam como fonte de empoderamento baseado no aprendizado, consolidando um ambiente de consumo alimentar mais consciente e democrático.

À luz desse referencial, tem-se tentado trazer à tona o potencial de geração de renda a partir dos produtos da roça de toco, contribuindo para romper o preconceito de que esse sistema tem condições de gerar produtos apenas para o consumo próprio.

\section{A COMERCIALIZAÇÃO DOS PRODUTOS DA ROÇA DE TOCO DE BIGUAÇU}

Em Biguaçu, os principais produtos oriundos do sistema roça de toco destinados ao mercado são a lenha, o carvão vegetal, o aipim, a farinha de mandioca e a banana. Outros produtos como feijão, milho e batata doce são geralmente produzidos para o autoconsumo. Pode-se dizer que a comercialização da farinha produzida no sistema de roça de toco, mesmo aquela que ainda permanece sem identificação, ocorre nos moldes de cadeias curtas de proximidade espacial, com destaque especial aos atributos de qualidade relacionados ao território.

No que diz respeito aos produtos de origem vegetal in natura, especialmente o aipim e a banana, uma característica comum está na comercialização a granel, em caixas, com a participação de intermediários, que entregam a produção nos centros de distribuição de onde os produtos seguem para o mercado local ou regional sem qualquer identificação quanto à procedência, origem ou qualificação. Neste caso, a comercialização acontece numa cadeia longa, em que as eventuais qualidades do produto ou de seu processo de produção passam despercebidas pelo consumidor. Uma única família de agricultores da região que processava minimante o aipim, descascando-o e embalando-o, vendia a sua produção artesanal em embalagens de filme plástico transparente, amarradas em uma das pontas. Constava da embalagem apenas a data de fabricação e a 
validade do produto, sendo a comercialização viabilizada por meio de circuitos curtos, diretamente ao consumidor ou, no máximo, por um intermediário que era parente próximo dos agricultores.

Quanto ao carvão vegetal, uma das formas de venda mais comum é a granel, em embalagens de cimento reutilizadas, igualmente sem rotulagem quanto à origem do produto (CARRIERI, 2014). Esta autora constatou que o carvão chega ao consumidor de várias formas: a) Venda direta em feiras livres, caracterizando uma cadeia curta face a face; b) Com a participação de intermediários, que entregam o produto em minimercados, pequenos comércios e churrascarias. Nesta situação, os consumidores reconhecem os atributos de qualidade do produto, associados ao seu local de origem, o que a caracteriza como uma cadeia curta de proximidade espacial; c) Com a participação de microempresas que embalam o carvão com sua marca, sem identificação individual dos produtores, e o distribuem tanto a minimercados quanto a mercados de maior porte, alcançando maiores distâncias em relação ao local de produção, por ter uma "roupagem regularizada" e por ser identificado como carvão de eucalipto, espécie exótica e livre de restrições de corte. Esta situação foi caracterizada pela autora como cadeia longa.

A autora destaca ainda que, embora clandestino, não há dificuldade de encontrar compradores para o carvão, por ser muito apreciado pelos consumidores, sendo a sua qualidade associada à origem e ao tipo de matériaprima. No entanto, essa situação gera muita angústia e baixa autoestima nos produtores que não podem estocar seus produtos, sob pena de serem fiscalizados e autuados por órgãos ambientais, vivendo constantemente em situação de estresse. Neste contexto, uma das características dos intermediários que são valorizadas pelos agricultores é o compromisso de recolher o produto tão logo seja retirado do forno.

Outro aspecto importante é que a impossibilidade de estocar e a clandestinidade da produção impõem limites à negociação do preço, que termina sendo determinado pelo intermediário.

No caso do carvão vegetal, é importante considerar que o distanciamento do órgão oficial de extensão rural e a relação conflituosa com os órgãos ambientais não permitiam que informações sobre a legislação ambiental chegassem de forma correta ao agricultor. Sendo assim, a possibilidade de realizar todas as etapas da produção de carvão de forma regularizada, embora existisse, soava aos agricultores como uma utopia. O agricultores entendiam que era "proibido fazer carvão de [lenha] nativa", o que gerava um círculo vicioso de falta de entendimento, desconfiança e imobilidade.

Com isso, queremos dizer que por diversos motivos os órgãos ambientais 
e de assistência técnica ainda eram agentes alheios à rede de mercado em que os agricultores transitavam, e que, para ultrapassar os limites impostos pelo embeddeness, era necessário que esses agentes fossem incluídos em uma proposta que visasse à construção de mercados para os produtos da roça toco, tendo como foco a autonomia dos agricultores, especialmente no mercado do carvão, cujo trânsito exige regularizações ambientais específicas.

O carvão produzido em Biguaçu, oriundo do sistema roça de toco, é muito procurado no âmbito da cadeia curta informal, conforme destacamos anteriormente, devido à sua qualidade intrínseca e não pelas características do sistema de uso da terra de onde provém a lenha. Sendo assim, quando comercializado nas embalagens informais (sacos de cimento), sem qualquer informação ao consumidor, o atributo de qualidade associado à sua origem em um sistema cujos benefícios socioambientais vêm sendo revalorizados, não consegue ser transmitido ao consumidor. O mesmo acontece quando é embalado como "carvão de eucalipto". Assim, em ambos os casos o potencial de valor agregado é limitado pela falta de estratégias de diferenciação que comuniquem ao consumidor as qualidades do produto e do processo de produção, de modo que o produtor não consegue impor o seu preço, mas sim ser tomador de preço.

Então, tornava-se necessário, como pontuamos acima, encontrar formas de sinalização de qualidade que substituíssem "a falta dos conhecimentos tácitos da rede de origem” (WILKINSON, 2008, p. 101). No entanto, essa sinalização também deveria apontar, sobretudo, para a qualidade do processo de produção: o potencial ecológico da roça de toco.

No caso do aipim descascado, as possibilidades de comercialização começaram a diminuir devido à exigência, por parte do comércio varejista, de melhor apresentação das embalagens, que deveriam ser seladas e não apenas amarradas. Assim, as normas formais de comercialização estavam se impondo aos canais de comercialização que tinham sido abertos com base nos laços fortes da rede social de origem dos agricultores. Embora por outro motivo, mas de modo semelhante ao que vinha acontecendo com o carvão, evidenciava-se a necessidade de novos mecanismos para alcançar mercados além da rede social de origem.

No caso dos engenhos de farinha ainda em funcionamento, quatro deles comercializam apenas na cadeia curta face a face, e os agricultores entendem que essa forma de comercialização não lhes oferece riscos e lhes garante clientela e bom preço. O quinto engenho, além da venda direta no próprio estabelecimento, comercializava o seu produto nos mercados varejistas do município de Biguaçu e de municípios vizinhos, e vinha sendo cobrado quanto à regularização fiscal da 
produção, considerando as normas voltadas à comercialização de alimentos. Mais adiante abordaremos a mudança de estratégia deste último engenho, no âmbito das inovações implementadas junto ao grupo de agricultores.

Esse conjunto de elementos tornou-se uma questão crucial nas relações dos agricultores familiares da roça de toco com o mercado, pois, como a produção, o processamento e a comercialização do produto eram informais, a sua diferenciação e valorização se limitavam aos conhecimentos no âmbito das redes sociais de origem, e no que se refere à qualidade intrínseca dos produtos. Mais do que isso, pode-se dizer que apenas a farinha de mandioca conseguia ser bem valorizada, alcançando o preço de $\mathrm{R} \$ 5,00$ por quilo pago ao produtor, sendo vendida diretamente no estabelecimento rural. Os outros produtos (carvão e aipim) conseguiam transitar no mercado devido ao embeddedness, mas não conseguiam alcançar preços diferenciados.

Assim, a comercialização dos produtos da roça de toco se constituía em um exemplo do que Moschini et al. (2008) se referem ao afirmar que a oferta de mercado de qualidade é composta por dificuldades relativas à assimetria de acesso à informação. Portanto, quando os produtores não apresentam um selo que ateste a sua qualidade, os consumidores definem suas escolhas na qualidade média percebida no mercado.

Para superar isso, os trabalhos com os agricultores apoiaram-se em Kotler e Keller (2006), quando afirmam que uma das formas de sinalizar ao mercado os elementos de qualidade diferenciados dos produtos de qualquer natureza é a criação e utilização de marcas, as quais devem ter uma designação singular, uma palavra ou um conceito, slogan, cores que a diferenciem dos demais símbolos e logotipos, e um campo de associações que agregue à marca um valor mitológico e ideológico. Esse conjunto de atributos traduzidos pelo design e exibidos em uma marca permite ao consumidor identificar o diferencial do produto, como o processo produtivo e a procedência, influenciando no processo de escolha de um produto que contenha elementos da qualidade e diferenciação.

Entendia-se que essa questão era ainda mais relevante por se tratar do mercado de produtos originários de sistemas tradicionais de produção e residia na dificuldade dos agricultores de conseguirem, individualmente, comunicar ao consumidor os atributos de qualidade intrínsecos (cor, saboretc.) e extrínsecos (forma de cultivo, processo de beneficiamento, preservação da paisagem) de seus produtos por meio do uso de marcas ou selos distintivos.

No caso dos agricultores de Biguaçu, o desenvolvimento de marcas ou selos distintos por parte de cada produtor, de forma individualizada, para a adequada comunicação com o consumidor, era simplesmente inviável. Além disso, a 
produção baseada em sistemas tradicionais, como a roça de toco, apresenta uma íntima relação com o território, a cultura, a tradição e a paisagem locais. Ou seja, trata-se de elementos coletivos e difusos, que são de difícil apropriação individual na forma de direito de propriedade.

\section{INOVAÇÕES ORGANIZACIONAIS IMPLEMENTADAS E OS DESAFIOS PRESENTES}

Com base na interpretação da forma de comercialização resumida acima e no trabalho participativo sistemático com os agricultores, entendia-se que uma das alternativas viáveis seria o uso de marcas coletivas elaboradas com o apoio do design, congregando elementos do território, dos saberes, da paisagem e da cultura locais, como uma forma inclusiva e democrática de diferenciar os produtos nos mercados competitivos.

No entanto, como as marcas coletivas advêm de um processo de inovação, elas geram um direito de propriedade; e esse direito requer o registro no órgão competente para proteger os detentores da marca do uso indevido por terceiros. Era necessário, então, que os agricultores avançassem para alguma forma coletiva de gestão da marca que viessem a criar - e esse foi o desafio que agricultores e técnicos enfrentaram, e que resultou na formação da Associação Valor da Roça, em julho de 2013. Neste sentido, atualmente, um grupo de agricultores constitui uma organização formal, na categoria de associação, no intuito de valorizar o mesmo sistema tradicional de uso da terra que antes os estigmatizava como "criminosos ambientais".

No entanto, a formação da associação resulta do amadurecimento do grupo. Inicialmente os agricultores decidiram elaborar embalagens coletivas para cada um dos principais produtos - carvão, farinha e aipim. Decidiram também que as três embalagens deveriam ter uma identidade visual única que remetesse ao elemento comum aos produtos: a sua origem no sistema roça de toco. A marca escolhida para o carvão foi "Nosso Carvão" - sugestão dos agricultores para fazer referência ao Projeto de mesmo nome, que foi pioneiro em abordar especificamente a produção de carvão naquela comunidade. Para a farinha e para o aipim, em alusão ao fator comum, optou-se pelos nomes "Nossa Farinha" e "Nosso Aipim".

Posteriormente, o grupo decidiu que essas marcas estariam amparadas por uma marca guarda-chuva, que poderia englobar novos produtos que viessem a ser produzidos pelo grupo, a qual recebeu o nome de "Valor da Roça" (Figura 1). 
Figura 1a-d. Marca "Valor da Roça”" e seus produtos

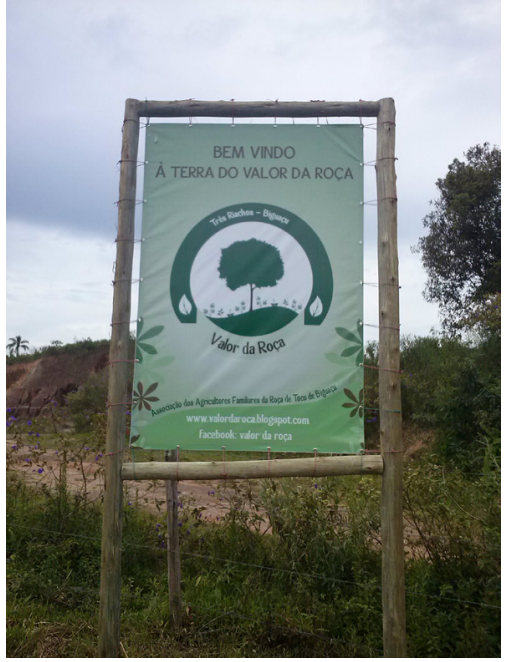

a) Outdoor com a marca Valor da Roça fixado na entrada da Localidade de Três Riachos (Biguaçu, SC)

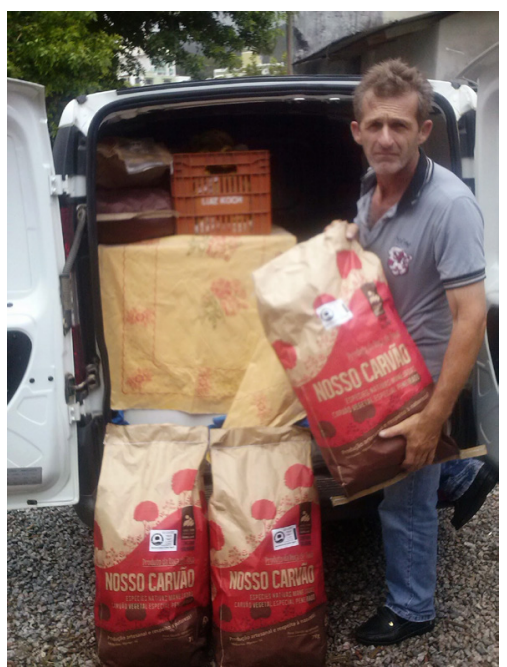

c) Agricultor fazendo entrega de sacos do Nosso Carvão - carvão vegetal da marca Valor da Roça.

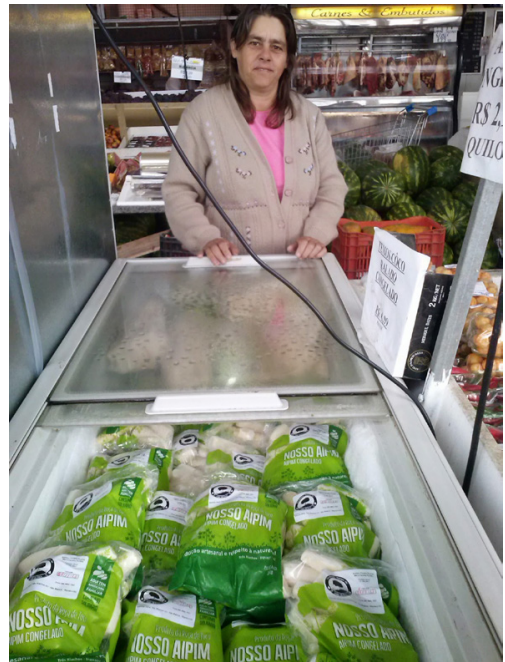

b) Agricultora ao lado do freezer abastecido com Nosso Aipim - aipim congelado da marca Valor da Roça.

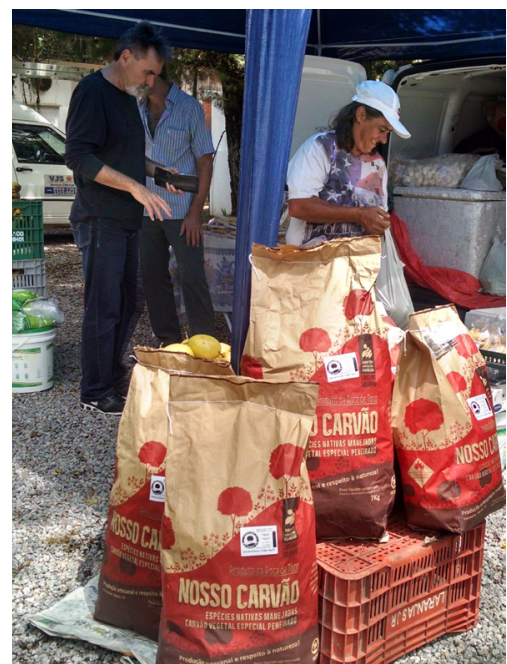

d) Produtos Valor da Roça sendo vendidos diretamente ao consumidor em feira semanal.

Fotos: Reney Dorow. 
A partir de então, passou-se a discutir e decidir as normas que regeriam o uso das embalagens e das marcas coletivas, processo que culminou na elaboração do Caderno de Normas.

Para garantir uma relação de confiança a ser construída em bases sólidas, com transparência de atitudes dos agricultores, decidiu-se criar um Grupo de Autocontrole formado por agricultores do próprio grupo, que fazem vistorias periódicas aos estabelecimentos dos associados para verificar e registrar a adequação das suas práticas às normas estabelecidas em um Caderno de Normas, também elaborado coletivamente.

A partir desses avanços, as discussões quinzenais do grupo levaram à conclusão de que era necessário criar uma organização formal para assegurar os direitos de propriedade das marcas. Para tanto, decidiu-se pela formação da Associação dos Agricultores Familiares da Roça de Toco de Biguaçu - Associação Valor da Roça.

É importante destacar que também fazem parte da Associação alguns agricultores que são intermediários de carvão, incentivados pelos agricultores que lhes forneciam carvão. Dessa forma, preservaram as relações de confiança anteriormente existentes entre esses agentes, conforme sugerido por Carrieri (2010).

Sob as normas acima descritas, os produtos Valor da Roça estão sendo vendidos em estabelecimentos da Grande Florianópolis, incluindo bairros centrais da capital catarinense. Alguns produtores já se lançaram sozinhos no mercado, independentes de intermediários, conseguindo auferir melhor renda, no entanto, sem afetar as relações de amizade com os antigos intermediários, que também são associados. A possibilidade de estocar o carvão sem risco de autuação pelos órgãos ambientais aumenta o poder de barganha dos agricultores, uma vez que podem aguardar e negociar uma oferta melhor.

Dados preliminares apontam que alguns produtores dobraram o valor de venda do carvão e também do aipim. No caso da farinha, o único produtor associado conseguiu voltar a atuar no mercado formal, conquistando inclusive outros pontos de venda, embora o preço recebido não tenha alterado muito em relação ao anterior, que já era satisfatório. Esta família relatou que a embalagem identificada permitiu o contato com novos consumidores, que procuraram os agricultores interessados em conhecer o processo de fabrico da farinha.

Do ponto de vista da abordagem das cadeias produtivas, com a comercialização iniciada por esse grupo estabeleceu-se então uma cadeia curta espacialmente estendida, cuja embalagem apresenta aos consumidores os elementos distintivos de qualidade, relacionados, sobretudo, ao processo de 
produção. No caso do carvão, o estabelecimento desse tipo de cadeia é muito importante, pois é uma forma de comunicar ao consumidor a regularidade ambiental da produção, que obedece às rígidas normas ambientais.

$\mathrm{O}$ conjunto de ações que levou à regularização e à organização dos agricultores da roça de toco no município de Biguaçu possibilitou um ambiente favorável para a conversão de produtos sem valor agregado em produtos com ascensão para mercados diferenciados, devido à reinterpretação do sistema de produção, da paisagem, da cultura e da tradição locais. Isso só foi possível a partir da criação da Associação que serve de alicerce para o registro dos direitos coletivos de propriedade (Figura 2).

No entanto, passados oito meses de sua formalização, enquanto alguns agricultores conseguiram dobrar o valor recebido pelos seus produtos, outros ainda se mantinham estagnados, especialmente no caso do carvão. Um deles alega que não gostaria de desfazer as antigas parcerias de comercialização; e outros alegam que seus compradores ainda não acreditam que o carvão acondicionado na nova embalagem tenha a mesma qualidade que o carvão comercializado nas embalagens de cimento reutilizadas. Por outro lado, a sensação de "ser tratado como gente" é unânime entre todos - expressão frequentemente mencionada, que revela o aumento da autoestima do grupo, por ter conseguido o acesso regularizado ao mercado.

A partir da discussão ocorrida durante a reunião realizada em abril de 2014, o grupo percebeu que há possibilidades de mercado que demandam uma quantidade maior de produto do que um produtor é capaz de atender de forma individual. Assim, concluiu-se que é possível administr as vendas de forma coletiva para alcançar novos mercados, sem precisar romper as parcerias antigas. Ao contrário, é possível fortalecê-las para atender coletivamente as demandas de mercado que valorizem adequadamente o carvão diferenciado.

Tendo em conta que, segundo Mendes e Padilha Jr. (2007), a comercialização é um processo planejado e encadeado, em que a produção é uma resultante do planejamento do potencial comércio dos produtos agrícolas, entendemos que a situação descrita acima se caracteriza por dois novos desafios:

a) Para os agricultores de forma individual: planejar a sua propriedade, levando em consideração os objetivos coletivos da associação, de modo a contribuir para atender às demandas de mercado que valorizem mais os produtos, e ao mesmo tempo perpetuar o sistema de roça de toco; e que esse planejamento seja inteligível ao órgão ambiental licenciador;

b) Para os agricultores de forma coletiva, no âmbito da Associação: planejar as decisões do grupo e aprender a tomar as decisões de forma coletiva, bem como 
desenvolver estratégias para envolver outros agentes além da sua rede social, para alcançar mercados diferenciados.

Como já mencionado, um aspecto que tem se mostrado fundamental para que a possibilidade de mercado diferenciado se consolide é a preservação do modo tradicional de produção e o seu monitoramento, de tal forma que permita a comprovação, a qualquer tempo, da legitimidade das ações realizadas no estabelecimento rural. Portanto, faz-se necessário estabelecer um procedimento de planejamento do uso da terra sob o sistema de roça de toco, passível de ser comunicado e entendido pelos demais agentes sociais interessados na manutenção desta prática, entre eles os consumidores e os órgãos ambientais.

Esta constatação vai ao encontro da análise de Batalha et al. (2004), quando apontam que na agricultura familiar a aplicação das tecnologias de gestão pode se dar em duas esferas: uma relativa às organizações associativas, das quais grande parte dos agricultores familiares participam (cooperativas e associações); e outra relativa à própria gestão do estabelecimento rural. Estes autores ressaltam a necessidade de aprimorar a gestão para que os agricultores familiares possam vencer os desafios de qualidade impostos pelos clientes (consumidores finais ou indústrias), referindo-se, sobretudo, às características do produto em si, que dificilmente alcança a padronização muitas vezes pretendida pelo consumidor. Dessa forma, alertam que "para os agricultores familiares, trata-se de adotar tecnologias de produto, processo e gestão que reconheçam esta variabilidade e a valorizem da melhor forma possível no mercado" (Idem).

Ferramentas apropriadas de gestão da qualidade e de planejamento e controle da produção, que padronizem normas e procedimentos intra e inter propriedades de uma dada rede de produção (se for o caso) e abram canais de comunicação com os clientes e fornecedores, são fundamentais para diminuir a variabilidade da quantidade e da qualidade da produção. Neste campo a informação é um insumo essencial, e escasso, no meio dos agricultores familiares (BATALHA et al., 2004, p. 6).

Por outro lado, os mesmos autores são enfáticos ao afirmar que as iniciativas de agregação de valor através do apelo a vários aspectos como a territorialidade dos alimentos produzidos, o caráter social da agricultura familiar, o sabor vinculado aos processos artesanais ou a justiça social vinculada à remuneração dos agricultores familiares são oportunidades que estão "longe de viabilizar a agricultura familiar tradicional, e dependem, todas elas, de capacidade de inovação dos produtores e de condições para superar as restrições da produção individual" (BATALHA et al., Op. cit., p. 2). 
Assim, é preciso desenvolver formas coletivas de trabalho, que levem em conta os mesmos critérios usados para avaliar o desempenho das unidades de produção agrícola em particular, de forma que se consiga acessar coletivamente mercados impossíveis para inclusão de cada agricultor de forma individualizada. Um exemplo concreto ocorreu em 2014, quando os agricultores da Associação Valor da Roça, por ainda não estarem suficientemente organizados, não puderam participar do Programa de Alimentação Escolar, do Governo Federal, que lhes permitiria conseguir um preço muito melhor para vários produtos, em relação ao valor que normalmente recebem.

\section{CONSIDERAÇÕES FINAIS}

Os sistemas tradicionais de produção constituem um dos grandes temas da agricultura mundial, pelo seu potencial ecológico, cultural e socioeconômico e, portanto, não podem passar despercebidos no contexto atual. Abordar a capacidade de inserção dos agricultores familiares no mercado, retirando-os da clandestinidade, requer um olhar diferenciado, sob a ótica de várias disciplinas. O desafio consiste em abordar essas práticas de forma sistêmica, possibilitando o envolvimento crítico dos agricultores, técnicos, consumidores e dos agentes ambientais - estes últimos quase sempre distantes da prática agrícola.

Este trabalho constata que é possível a geração de renda monetária por meio da comercialização de produtos da roça de toco, e que é possível alcançar mercados diferenciados para melhorar os rendimentos e a autoestima dos agricultores a partir de estratégias de diferenciação dos produtos e do processo de produção. Mas é importante desenvolver processos coletivos de organização e criação de elementos a serem usados pelos agricultores visando influenciar a decisão dos consumidores quanto à singularidade e à função múltipla do sistema de produção.

Por fim, os profissionais que atuam junto às populações rurais, geralmente egressos dos cursos das Ciências Agrárias, precisam compreender que, assim como se demonstra neste artigo, as práticas e normas sociais (formais ou informais) são construídas socialmente, e que os agentes técnicos têm a possibilidade e o dever de agir para transformar determinadas situações. 


\section{REFERÊNCIAS}

ARRUDA, R. S. V. Populações tradicionais e a proteção dos recursos naturais em unidades de conservação. In: DIEGUES, A. C. (Org.). Etnoconservação. Novos rumos para a proteção da natureza nos trópicos. 2. ed. São Paulo: Annablume; USP, 2002.

ADAMS, C.; MUNARI, L. C.; VAN VLIET, N.; MURRIETA, R. S. S.; PIPERATA, B. A.; FUTEMMA, C.; PEDROSO Jr., N. N.; TAQUEDA, C. S.; CREVELARO, M. A.; SPRESSOLA-PRADO, V. L. Diversifying Incomes and Losing Landscape Complexity in Quilombola Shifting Cultivation Communities of the Atlantic Rainforest (Brazil). Human Ecology, v. 41, p. 119-137, 2013.

AUBRI, C.; CHIFFOLEAU, Y. Le développement des circuits courts et l'agriculture périurbaine: histoire, évolution em cours et questions actuelles. Innovations Agronomiques, v. 5, p. 53-97, 2009.

BATALHA, M. O.; SILVA, A. L. Gerenciamento de sistemas agroindustriais: definições, especificidades e correntes metodológicas. In: BATALHA, M. O. (Coord.). Gestão agroindustrial. 3. ed. São Paulo: Atlas, 2012. v. 1, p. 1-62.

BATALHA, M. O.; BUAINAIN, A. M.; SOUZA FILHO, H. M. de. Tecnologia de gestão e agricultura familiar. In: CONGRESSO BRASILEIRO DE ECONOMIA, ADMINISTRAÇÃO E SOCIOLOGIA RURAL, 42, 2004, Cuiabá. Anais... Cuiabá: SOBER, 2004. CD-ROM.

BATALHA, M. O. Gestão agroindustrial. São Paulo: Atlas, 1997. 770p. v.1.

BAUER, E. Mudanças no uso da terra em Biguaçu-SC: agricultores em permanente processo de adaptação. 2012. Dissertação (Mestrado em Agroecossistemas) - Universidade Federal de Santa Catarina, Florianópolis, 2012.

CARRIERI, M. Estudo exploratório sobre o sistema de produção e a comercialização do carvão vegetal produzido por agricultores familiares da microbacia de São Mateus (Biguaçu/SC). 2010. Trabalho de Conclusão de Curso (Graduação em Agronomia) - Centro de Ciências Agrárias, Universidade Federal de Santa Catarina, Florianópolis, 2010.

CARRIERI, M. Cadeias produtivas do carvão vegetal na agricultura familiar no Sul do Brasil. 2014, 193 f. Dissertação (Mestrado em Agroecossistemas) - Centro de Ciências Agrárias, Universidade Federal de Santa Catarina, Florianópolis, 2014. 
CHAFFOTTE, L.; CHIFFOLEAU, Y. Vente directe et circuits courts: évaluations, définitions et typologie. Cahiers de l'Observatoire CROC, Montpellier, n. 1-2, fev.-mar. 2007.

DEAN, W. With Broadax and Firebrand: the destruction of the Brazilian Atlantic Forest. Berkeley: University of California Press, 1997.

GRANOVETTER, M. The strength of weak ties. American Journal of Sociology, v. 78, n. 6. p. 1360-1380, 1973.

KOTLER, P.; KELLER, K. Administração de Marketing, 12 .ed. São Paulo: Pearson Printice Hall, 2006.

LEVKOE, C. Learning democracy through food justice movements. Agriculture and Human Values, v. 23, p. 89-98, 2006.

LUCA, F. V. "Botar a roça": agricultura de corte e queima e manejo de bracatingais emBiguaçu, SC. 2011. 77f. Trabalho de Conclusão de Curso (Graduação em Agronomia) - Centro de Ciências Agrárias, Universidade Federal de Santa Catarina, Florianópolis, 2011.

MARSDEN, T.; BANKS, J.; BRISTOW, G. Food supply chain approaches: exploring their role in rural development. Sociologia Ruralis, Oxford, v. 40, n. 4, p. 424-438, 2000.

MAZUCHOWSKI, J. Z. Sistema de produção de bracatinga (Mimosa scabrella Benth.) sob técnicas de manejo silvicultural. 2012. 218f. Tese (Doutorado em Silvicultura) - Setor de Ciências Agrárias, Universidade Federal do Paraná, Curitiba, 2012.

MOSCHINI, G. C.; MENAPACE, L.; PICK, D. Geographical indications and the competitive provision of quality in agricultural markets. American Journal Agricultural Economics, v. 90, n. 3, p. 794-812, 2008.

NASCIMENTO, A. M.; REGINATO, L. Divulgação da informação contábil, governança corporativa e controle organizacional: uma relação necessária. Revista Universo Contábil, v. 4, n. 3, p. 25-47, 2008.

RENTING, H.; MARSDEN, T.; BANKS, J. Understanding alternative food networks: exploring the role of short food supply chains in rural development. Environment and Planning A, London, v. 35, p. 393-411, 2003.

SANTA CATARINA. Lei no 16.342 de 21 de janeiro de 2014. Altera a Lei $n^{\circ}$ 14.675, de 2009, que institui o Código Estadual do Meio Ambiente e estabelece outras previdências. Diário Oficial Estado de Santa Catarina, Florianópolis, 
22 jan. 2014.

STEENBOCK, W. Domesticação de bracatingais: perspectivas de inclusão social e conservação ambiental. 2009, 281f. Tese (Doutorado em Recursos Genéticos Vegetais) - Centro de Ciências Agrárias, Universidade Federal de Santa Catarina, Florianópolis, 2009.

STEEMBOCK, W.; REIS, M. S. Domesticação da paisagem em bracatingais de assentamento rurais do Planalto Catarinense. Ciência Florestal, Santa Maria, v. 23, n. 3, p. 427-437, jul.-set., 2013.

ULLER-GÓMEZ, C.; GARTNER, C. Um caminho para conhecer e transformar nossa comunidade. Relatório Final. Florianópolis: Epagri/MB2, 2008.

VAN-VLIET, N.; MERTZ, O.; HEINIMANN, A.; LANGANKE, T.; PASCUAL, U.; SCHMOOK, B.; ADAMS, C.; SCHMIDT-VOGT, D.; MESSERLI, P.; LEISZ, S.; CASTELLA, J. C.; JØRGENSEN, L.; BIRCH-THOMSEN, T.; HET'T, C.; BRUUN, T. B.; ICKOWITZ, A.; VU, K. C.; FOX, J.; CRAMB, R. A.; PADOCH, C.; DRESSLER, W.; ZIEGLER, A. Trends, drivers and impacts of changes in Swidden cultivation in tropical forest agriculture frontiers: a global assessment.

Global Environmental Change, Boston, v. 22, p. 418-429, 2012.

WILKINGS, J. Eating right here: moving from consumer to good citizen. Agriculture and Human Values, v. 22, n. 3, p. 269-273, 2005.

WILKINSON, J. Mercados, redes e valores. Porto Alegre: EdUFRGS, 2008. 213p.

WOORTMANN, K. Com parente não se neguceia. O campesinato como ordem moral. In: Anuário Antropológico, 87. Brasília: UNB; Rio de Janeiro: Tempo Brasileiro, 1990. p.11-73. 


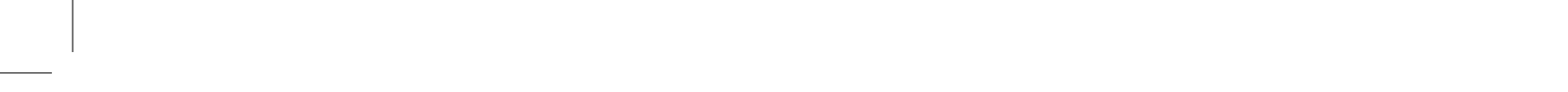

